\title{
CHARACTERISTICS OF A TWO-PHASE SRM WITH DIFFERENT ROTOR DESIGNS BASED ON FINITE ELEMENT ANALYSIS
}

\author{
Waleed. A. Afifi \\ Egyptian Railways Maintenance \\ and Services Company
}

\author{
M. M. Khater \\ Faculty of Engineering \\ Menoufiya University
}

\author{
M. A. El-Khazendar \\ Faculty of Engineering, \\ Tanta University
}

\begin{abstract}
This paper presents the operating performance of a two-phase switched reluctance motor with different rotor designs, having different air gap geometries. A two-dimension finite element analysis is used to predict the nonlinear flux linkage characteristics for the different rotor designs. The characteristics are obtained numerically at different rotor positions and different current levels for the rotor designs under consideration and then used to predict the static torque characteristics for these designs. A computer simulation procedure is devised to determine the operating performances for the different motor designs based on the predicted flux linkage and static torque characteristics. A comparison is held from the point of view of the torque developed at different speeds, motor efficiency and torque per ampere productivity of the different designs. The twostepped air gap design proved the superiority over the other configurations.

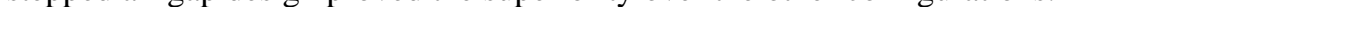

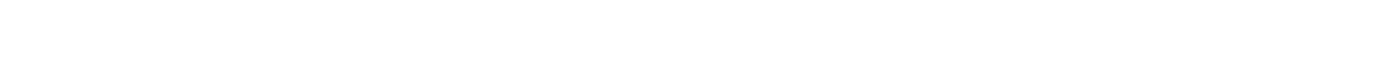

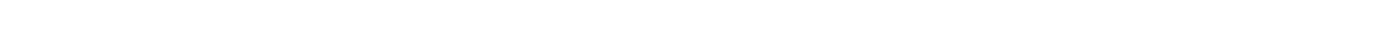

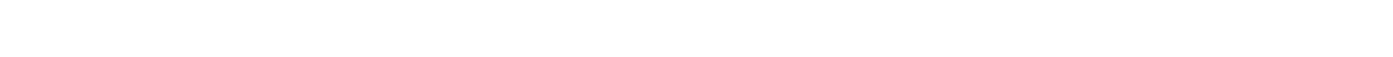

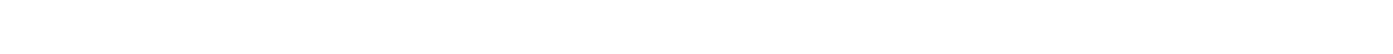

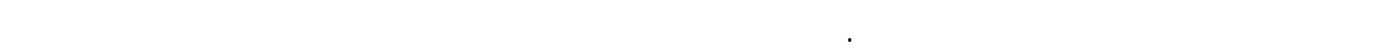

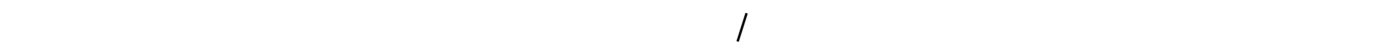

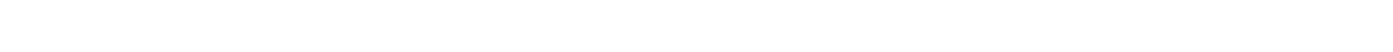

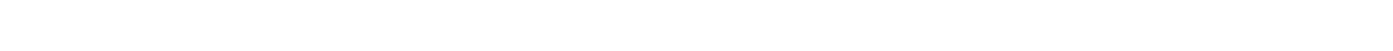

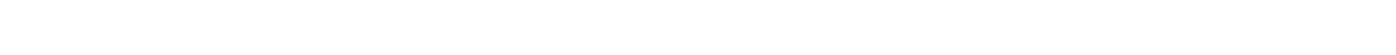

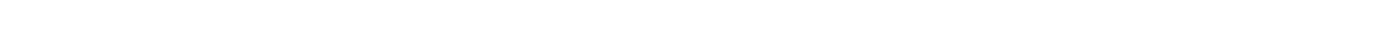

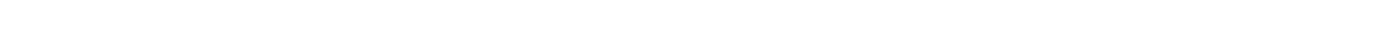

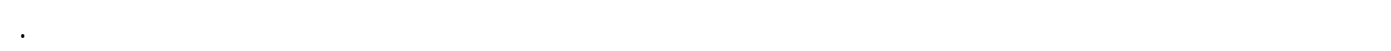
Keywords: Switched Reluctance Motors (SRM), Magnetic Circuits, Finite Element.

\section{INTRODUCTION}

Switched reluctance motor (SRM) is characterized by its simple, rugged motor construction and easy control process such that its operating performances can be tailored to satisfy numerous applications. In spite of the great number of literature reported about SRM, the main interest is concerned with multi-phase designs. However there are many advantages can be obtained from motor designs of low number of phases such as high speed levels, low iron losses, and low number of devices required for the driving power electronic circuit. These advantages are attractive for power drives utilized in hand tools and light domestic appliances. Traditionally, these applications employ single-phase induction or universal motors. These motors, although their reliability and low cost, they have several drawbacks such as poor efficiency, low torque capability, commutator/brush wear with high electromagnetic interference especially in the universal motor. For this reason the SRM emerges a good solution that joins high reliability, good torque characteristics, high efficiency and low cost. The two-phase 4/2 pole, SRM is the simplest electromagnetic structure available for this motor [15]. The $4 / 2$ topology is a doubly salient structure of radial steel laminations which has four stator saliencies wound such that each two diametrically opposite coils are connected to compose one phase, while the rotor has only two saliencies without any windings $[2,6]$.

Like other types of SRMs, the torque developed by the two-phase 4/2 SRM consists of successive pulse strokes. However, there is no overlap between these torque pulses, with the result of zero torque zones around the rotor periphery [4]. Different ways are proposed to overcome such problem [2,3,6-8]. Some authors proposed the introduction of a parking magnet to stop the rotor at a certain position of a positive torque for the next starting $[7,8]$. However, such parking magnet introduces two difficulties. The first is the fast deterioration due to the high level of 
vibration and magnetic noise inherent in SRMs. The second is the detent torque developed by this magnet which subtracts from the motor developed torque. An alternative solution introduces unsymmetrical magnetic flux distribution with respect to pole axis such that prolonged torque pulses with no zero zones are obtained. Unsymmetrical magnetic flux distribution is usually obtained by using irregular air gap over the rotor pole arc. Different air gap geometries were introduced for this purpose $[3,4]$. The introduction of different shapes of air gap geometries may be useful to enhance the motor starting; however in most cases it has a derating effect on the running performance of the motor. The operating performances still need to be studied and tested to justify a certain shape among different design alternatives. The operating performance of a SRM is highly dependent on the saturation level of its magnetic circuit. With irregular shapes of air gap the analysis of the magnetic circuit becomes more complicated. Finite element (FE) analysis has been proposed for such problem. Numerous research works have been recently reported on the use of FE for design and performance analysis of SRMs [9-16]. This method, however being tedious and need a lot of computation it is powerful for predicting the flux linkage properties of complex magnetic circuit shapes.

This paper investigates and compares the operating performance of a 4/2 pole, 2-phase SRM with four different rotor designs having different air gap geometries. The air gap shapes under investigation are chosen as a two-step air gap, onestep air gap, tapered air gap, and regular air gap as shown in Fig 1. A two-dimension finite element procedure for analyzing the magnetic circuit is proposed and implemented to predict the nonlinear flux linkage and static torque characteristics for different rotor designs. The operating performances are predicted and compared from the point of view of the torque developed at different speeds, motor efficiency and torque per ampere productivity of the different designs.

\section{MAGNETIC CIRCUIT ANALYSIS}

The study of the magnetic field distribution in proposed two-phase SRM is based on the four Maxwell equations which are expressed as;

$$
\begin{aligned}
& \nabla \times \overline{\mathrm{E}}=-\frac{\partial \overline{\mathrm{B}}}{\partial \mathrm{t}} \\
& \nabla \times \overline{\mathrm{H}}=\overline{\mathrm{J}_{\mathrm{e}}}+\overline{\mathrm{J}} \\
& \nabla . \mathrm{B}=0 \\
& \mathrm{H}=\mathrm{v} \mathrm{B}
\end{aligned}
$$

where

$$
\begin{array}{ll}
\overline{\mathrm{E}} & \text { Electric field intensity vector }[\mathrm{V} / \mathrm{m}] \\
\bar{B} & \text { Magnetic flux density vector }\left[\mathrm{Wb} / \mathrm{m}^{2}\right]
\end{array}
$$

$\overline{\mathrm{H}} \quad$ Magnetic field intensity vector $[\mathrm{A} / \mathrm{m}]$

$\overline{\mathrm{J}_{\mathrm{e}}} \quad$ Excitation current density vector $\left[\mathrm{A} / \mathrm{m}^{2}\right]$

$\overline{\mathrm{J}} \quad$ Induced current density vector $\left[\mathrm{A} / \mathrm{m}^{2}\right]$

$\checkmark$ Magnetic reluctivity of the medium.

In addition to Maxwell equations the key variable is the magnetic vector potential $\overline{\mathrm{A}}$, where; $\nabla \times \overline{\mathrm{A}}=\overline{\mathrm{B}}$

The two-dimension finite element method represented here is formulated under the following assumptions;

1. $A_{x}=A_{y}=0$, thus the magnetic field has two components $\mathrm{B}_{\mathrm{x}}, \mathrm{B}_{\mathrm{y}}$

2. $\mathrm{J}_{\mathrm{x}}=\mathrm{J}_{\mathrm{y}}=0$

3. The current density is uniform.

4. Hystersis effects are neglected.

5. The reluctivity of core iron are isotropic, i.e., $v_{x}=v_{y}=v_{z}=v$

6. The boundary field i.e. the field outside of the motor is assumed equal to zero.

7. The effects of holes and pins are neglected.

The finite element analysis of a magnetic circuit involves basically the following four steps [17]

1) Discretizing the solution region into a finite number of sub-regions or elements.

2) Deriving the governing equations for a typical element.

3) Assembling all elements of the solution region.

4) Solving the system of equations obtained.

These steps are explained in the following sections.

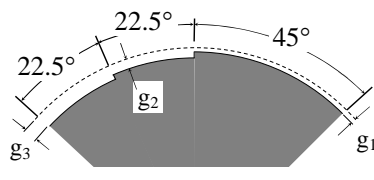

Two-steps air gap

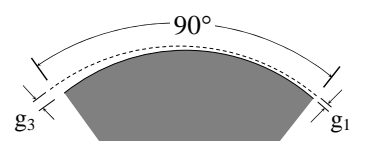

Tapered air gap

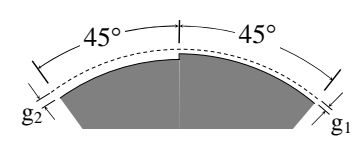

One-step air gap

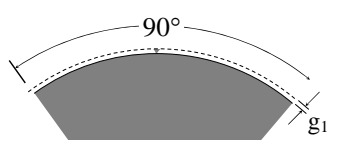

Regular air gap
Fig 1. The four different air gap geometries under investigation

\subsection{Finite Element Discretization}

The solution region is divided into a number of finite sub-regions which are called elements. An example is illustrated in Fig. 2 in which the region is subdivided into five no-overlapping elements and six nodes. The behavior of the magnetic field within these elements is usually expressed by a polynomial interpolation function which is usually of a first order 
type in terms of the space coordinates. These elements are referred to linear elements and the magnetic vector potential $\overline{\mathrm{A}}$ can be expressed as; $A(x, y)=a+b x+c y$

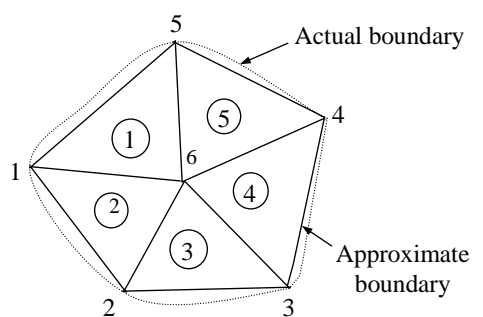

Fig. 2 A Typical Finite Element Subdivision of an Irregular Domain.

\subsection{Deriving Governing Equations for a Typical} Element

Consider a typical triangular element as that shown in Fig. 3 is an element of region.

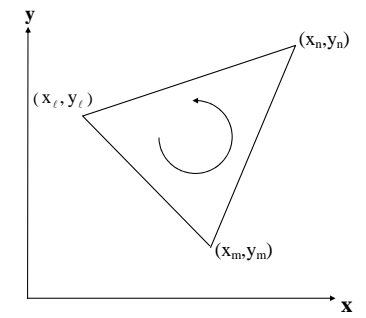

Fig. 3. A Typical Triangular Element.

The energy function for this element can be written as;

$F(\bar{A})=\iint_{S}\left[\frac{1}{2}(\bar{B} \cdot \bar{H})-\bar{J} \cdot \bar{A}\right] d x d y$

Where $\mathrm{S}$ is the area of the element.

Substituting in this equation from the previous one and minimizing with respect to the nodal values of the field variables, the value of the field variable must satisfy the Maxwell based partial differential equation governing the magnetic vector potential, that is;

$\frac{\partial}{\partial \mathrm{x}}\left(v \frac{\partial \mathrm{A}_{\mathrm{z}}}{\partial \mathrm{x}}\right)+\frac{\partial}{\partial \mathrm{y}}\left(\mathrm{v} \frac{\partial \mathrm{A}_{\mathrm{z}}}{\partial \mathrm{y}}\right)=-\mathrm{J}_{\mathrm{z}}$

Where $\mathrm{A}_{\mathrm{Z}}=\mathrm{A}$ within the triangular element area at any point $(\mathrm{x}, \mathrm{y})$ in terms of the magnetic vector potential values at the triangular nodes $\ell, m, n$ respectively.

$\mathrm{A}(\mathrm{x}, \mathrm{y})=\alpha_{\ell} \mathrm{A}_{\ell}+\alpha_{\mathrm{m}} \mathrm{A}_{\mathrm{m}}+\alpha_{\mathrm{n}} \mathrm{A}_{\mathrm{n}}$

Where $\alpha$ 's are called the elements shape functions and they are first order polynomials of the following properties;

$\alpha_{i}\left(x_{i}, y_{j}\right)= \begin{cases}1 & i=j \\ 0 & i \neq j\end{cases}$ $\sum_{i=1}^{3} \alpha_{i}(x, y)=1$

Where $\mathrm{i}$ and $\mathrm{j}=\ell, \mathrm{m}, \mathrm{n}$

$\alpha_{\mathrm{i}}(\mathrm{x}, \mathrm{y})=\mathrm{k}_{\mathrm{i} \ell}+\mathrm{k}_{\mathrm{im}} \mathrm{x}+\mathrm{k}_{\mathrm{in}} \mathrm{y}$

By substituting in Eqn (12) $\mathrm{i}=\ell$, m, $\mathrm{n}$ the following expression can be obtained;

$\left[\begin{array}{c}\alpha_{\ell}(\mathrm{x}, \mathrm{y}) \\ \alpha_{\mathrm{m}}(\mathrm{x}, \mathrm{y}) \\ \alpha_{\mathrm{n}}(\mathrm{x}, \mathrm{y})\end{array}\right]=\left[\begin{array}{ccc}\mathrm{k}_{\ell \ell} & \mathrm{k}_{\ell \mathrm{m}} & \mathrm{k}_{\ell \mathrm{n}} \\ \mathrm{k}_{\mathrm{m} \ell} & \mathrm{k}_{\mathrm{mm}} & \mathrm{k}_{\mathrm{mn}} \\ \mathrm{k}_{\mathrm{n} \ell} & \mathrm{k}_{\mathrm{nm}} & \mathrm{k}_{\mathrm{nn}}\end{array}\right]\left[\begin{array}{l}1 \\ \mathrm{x} \\ \mathrm{y}\end{array}\right]$

And can show that

$\left[\begin{array}{ccc}\mathrm{k}_{\ell \ell} & \mathrm{k}_{\ell \mathrm{m}} & \mathrm{k}_{\ell \mathrm{n}} \\ \mathrm{k}_{\mathrm{m} \ell} & \mathrm{k}_{\mathrm{mm}} & \mathrm{k}_{\mathrm{mn}} \\ \mathrm{k}_{\mathrm{n} \ell} & \mathrm{k}_{\mathrm{nm}} & \mathrm{k}_{\mathrm{nn}}\end{array}\right]=\left[\begin{array}{ccc}1 & \mathrm{x}_{\ell} & \mathrm{y}_{\ell} \\ 1 & \mathrm{x}_{\mathrm{m}} & \mathrm{y}_{\mathrm{m}} \\ 1 & \mathrm{x}_{\mathrm{n}} & \mathrm{y}_{\mathrm{n}}\end{array}\right]^{-1}$

$\left[\begin{array}{ccc}\mathrm{k}_{\ell \ell} & \mathrm{k}_{\ell \mathrm{m}} & \mathrm{k}_{\ell \mathrm{n}} \\ \mathrm{k}_{\mathrm{m} \ell} & \mathrm{k}_{\mathrm{mm}} & \mathrm{k}_{\mathrm{mn}} \\ \mathrm{k}_{\mathrm{n} \ell} & \mathrm{k}_{\mathrm{nm}} & \mathrm{k}_{\mathrm{nn}}\end{array}\right]=$

$\frac{1}{2 M}\left[\begin{array}{ccc}\left(\mathrm{x}_{\mathrm{m}} \mathrm{y}_{\mathrm{n}}-\mathrm{x}_{\mathrm{n}} \mathrm{y}_{\mathrm{m}}\right) & \left(\mathrm{x}_{\mathrm{n}} \mathrm{y}_{\ell}-\mathrm{x}_{\ell} \mathrm{y}_{\mathrm{n}}\right) & \left(\mathrm{x}_{\ell} \mathrm{y}_{\mathrm{m}}-\mathrm{x}_{\mathrm{m}} \mathrm{y}_{\ell}\right) \\ \left(\mathrm{y}_{\mathrm{m}}-\mathrm{y}_{\mathrm{n}}\right) & \left(\mathrm{y}_{\mathrm{n}}-\mathrm{y}_{\ell}\right) & \left(\mathrm{y}_{\ell}-\mathrm{y}_{\mathrm{m}}\right) \\ \left(\mathrm{x}_{\mathrm{n}}-\mathrm{x}_{\mathrm{m}}\right) & \left(\mathrm{x}_{1}-\mathrm{x}_{\mathrm{n}}\right) & \left(\mathrm{x}_{\mathrm{m}}-\mathrm{x}_{\ell}\right)\end{array}\right]$

Where $\mathrm{M}$ is the area of the element, i.e,

$2 \mathrm{M}=\left|\begin{array}{ccc}1 & \mathrm{x}_{\ell} & \mathrm{y}_{\ell} \\ 1 & \mathrm{x}_{\mathrm{m}} & \mathrm{y}_{\mathrm{m}} \\ 1 & \mathrm{x}_{\mathrm{n}} & \mathrm{y}_{\mathrm{n}}\end{array}\right|$

The value of $M$ is positive if the nodes are numbered counterclockwise (starting from any node). A solution is obtained by minimizing $F(\bar{A})$ with respect to $\overline{\mathrm{A}}$, that is:

$\frac{\partial \mathrm{F}(\overline{\mathrm{A}})}{\partial \mathrm{A}_{\mathrm{Z}}}=0$

And this equation can be written for every element;

$\mathrm{C}_{\mathrm{i}} \cdot \mathrm{A}_{\mathrm{i}}=\mathrm{I}_{\mathrm{i}}$

For example, for the element 1 in the shown region

$C_{1}=\left[\begin{array}{lll}C_{11} & C_{16} & C_{15} \\ C_{61} & C_{66} & C_{65} \\ C_{51} & C_{56} & C_{55}\end{array}\right], I_{1}=\frac{M_{1}}{3}\left[\begin{array}{c}J_{1} \\ J_{1} \\ J_{1}\end{array}\right]$ and $A_{1}=\left[\begin{array}{c}A_{11} \\ A_{61} \\ A_{51}\end{array}\right]$ where $C_{1}$ is called the element coefficient matrix and $\mathrm{J}_{1}$ is the current density in the element 1

\subsection{Assembling All Elements in the Solution Region}

The next step is to assemble all such elements in the solution region .In this step the individual element coefficient matrices are assembled to obtain the following global coefficient matrix; 


$$
\left[\begin{array}{cccccc}
\mathrm{C}(1)_{11}+\mathrm{C}(2)_{11} & \mathrm{C}(2)_{12} & 0 & 0 & \mathrm{C}(1)_{13} & \mathrm{C}(1)_{12}+\mathrm{C}(2)_{13} \\
\mathrm{C}(2)_{21} & \mathrm{C}(2)_{22}+\mathrm{C}(3)_{11} & \mathrm{C}(3)_{12} & 0 & 0 & \mathrm{C}(2)_{23}+\mathrm{C}(3)_{13} \\
0 & \mathrm{C}(3)_{21} & \mathrm{C}(3)_{22}+\mathrm{C}(4)_{11} & \mathrm{C}(4)_{12} & 0 & \mathrm{C}(3)_{23}+\mathrm{C}(4)_{13} \\
0 & 0 & \mathrm{C}(4)_{21} & \mathrm{C}(4)_{22}+\mathrm{C}(5)_{22} & \mathrm{C}(5)_{23} & \mathrm{C}(4)_{23}+\mathrm{C}(5)_{21} \\
\mathrm{C}(1)_{31} & 0 & 0 & \mathrm{C}(5)_{32} & \mathrm{C}(1)_{33}+\mathrm{C}(5)_{33} & \mathrm{C}(1)_{32}+\mathrm{C}(5)_{31} \\
\mathrm{C}(1)_{21}+\mathrm{C}(2)_{31} & \mathrm{C}(2)_{32}+\mathrm{C}(3)_{31} & \mathrm{C}(3)_{32}+\mathrm{C}(4)_{31} & \mathrm{C}(4)_{32}+\mathrm{C}(5)_{12} & \mathrm{C}(1)_{23}+\mathrm{C}(5)_{13} & \mathrm{C}(1)_{22}+\mathrm{C}(2)_{33}+ \\
& & & & & \mathrm{C}(3)_{33}+\mathrm{C}(5)_{11}
\end{array}\right]
$$

It should be noted that, there are always nodes shared by adjacent mesh elements. This node-share is always reflected on the properties of the global matrix, which can be stated as;

1. It is symmetric $\left(C_{i j}=C_{j i}\right)$ just as the element coefficient matrix.

2. Since $\mathrm{C}_{\mathrm{ij}}=0$ no coupling exists between nodes $\mathrm{i}$ and $\mathrm{j}$

3. It is singular.

\subsection{Solving the System Equations}

To solve the system equations it must be converted from a singular to a non-singular system. This condition can be satisfied by introducing the boundary conditions to obtain a unique solution. Dirichlet conditions are used since in this type of boundary condition, the value of magnetic vector potential at the external boundary is zero, $A=0$. In this way, it would be easy to calculate the flux density from the magnetic vector potential, and then the distribution of flux linkage inside the machine can obtained.

\subsection{Implementation of Finite Element Analysis}

The introduced finite element analysis procedure is implemented in a computer program to analyze magnetic circuit of the different motor design under consideration. The data and dimensions of these designs are given in Ref [18]. The program consists of the following three main program modules:

1. A program shell for laying out the motor geometry and for defining material properties and boundary conditions.

2. Discretization module for meshing or breaking the solution region into a certain number of triangles.

3. Solver module which calls a set of data files that describe the problem and solves the relevant Maxwell's Equations to obtain values for the desired field throughout the solution domain.

Magnetic circuit analysis is implemented with this program. Firstly, the magnetic circuit geometry is defined for each design, along with material properties and winding current. This data is then processed using meshing and solver modules to obtain the flux-linkage and flux distribution for the magnetic circuit at certain current level and rotor position angle. This process is repeated many times for different current levels and different rotor position angles to obtain a family of flux-linkage characteristic for each design.

\section{FLUX-LINKAGE CHARACTERISTICS}

It is well known that, the flux-linkage characteristic is periodic with a period equals the rotor pole pitch. The rotor pole pitch for the $4 / 2$ motor configuration equals $180^{\circ}$. Due to unsymmetrical rotor pole shape for all designs under investigation (except the case of regular rotor), finiteelement analysis is carried-out over the whole rotor pole pitch from zero to $180^{\circ}$ with a step angle of $\Delta \theta=2.5^{\circ}$. For each rotor position angle numerical solution has been repeated many times for different current levels starting from $I=0.5 \mathrm{~A}$ with increments of $\Delta I=0.5 \mathrm{~A}$ up to up to 20A to obtain enough data representing saturation.

A sample of FE analysis results are represented in Figs 4-7. Figure 4 shows flux contours for fully aligned, partially aligned and unaligned rotor positions respectively for two-steps rotor design. The aligned rotor position, represented by Fig. 4-a, has a minimum magnetic reluctance at which almost all flux lines pass through the stator and the rotor poles. It is observed that flux lines are too condensed at the pole edge of minimum air gap which reflects a high level of saturation in these parts. The phase inductance at this rotor position has its maximum value. In the midway between aligned and unaligned rotor positions as that shown in Fig. 4-b, the flux encounters a higher reluctance path so the inductance is lower than the first position. At an unaligned position, like that shown in Fig. 4-c, the flux encounters the highest reluctance, so the inductance is minimum.

The flux-linkage characteristic curves for the four motor designs represented as a function of phase excitation current for different rotor position angles are illustrated in Fig 5. Each set of data is obtained at regular rotor position angles starting from the lowest curve at unaligned position to the most upper curve at aligned position. It can be clearly observed that, for a fixed rotor position angle the flux linkage is 
generally represented by a nonlinear function of the stator phase current. Up to certain value of this current, the relationship is linear. As the current increases, saturation occurs, which means flux linkage becomes no longer linear. The larger current contributes the saturating effect as shown in Fig 5. The shown curves depict also a varying magnetic flux loading capability of the different motor types.

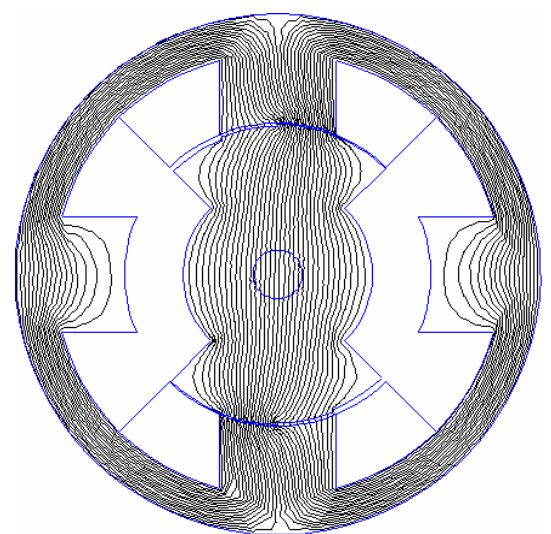

(4-a) Flux distribution at aligned position.

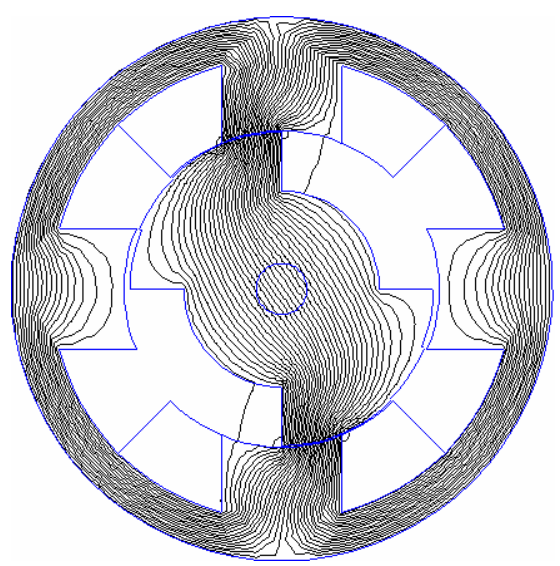

(4-b) Flux distribution at $45^{\circ}$ from aligned position.

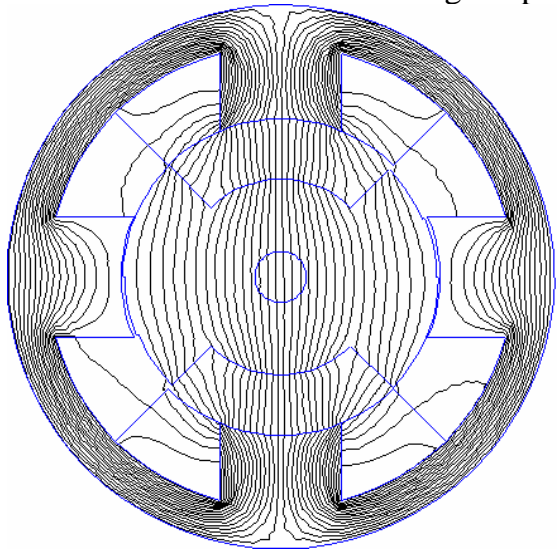

(4-c) Flux distribution at unaligned position.

Fig. 4. Flux distribution for two-steps rotor design at three different rotor position angles and excitation current $5 \mathrm{~A}$.
The flux linkage characteristic curves for the four motor designs are also represented as a function of rotor position angle at different phase excitation current as illustrated in Fig 6. These curves are presented as another way to represent the flux linkage data in order to clarify the previous observations. The low curves represent the flux linkage data at low excitation currents while the upper ones for higher currents. These characteristic curves are obtained at regular steps of excitation current however they become more condensed at high current levels due to magnetic saturation. It is observed that, for a fixed stator current, flux linkage is a periodic function of the rotor position angle with a period equal to the rotor pole pitch. Saturation level differs considerably for distinct rotor position angles such that the closer to the aligned position, the sharper the saturation effect becomes.

Figure 7 represents the flux linkage as a function of rotor position angle for the different designs under consideration at a similar excitation current level of 3A. From this figure it is clear that both the twostepped and regular air gap have the highest flux linkage, however the two-stepped one has a wider positive sloped region. This property is essential for prolonged torque pulses which enhance motor starting. Both one-step air gap and tapered one have comparable lower level of flux linkage. This level is important for torque production of SRM.

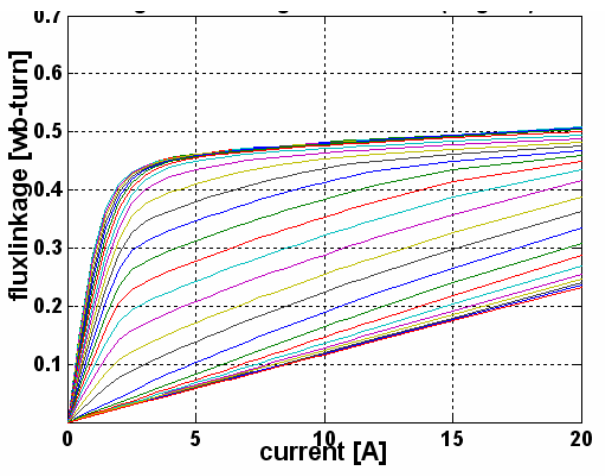

(5-a) Flux linkage characteristic curves of regular air

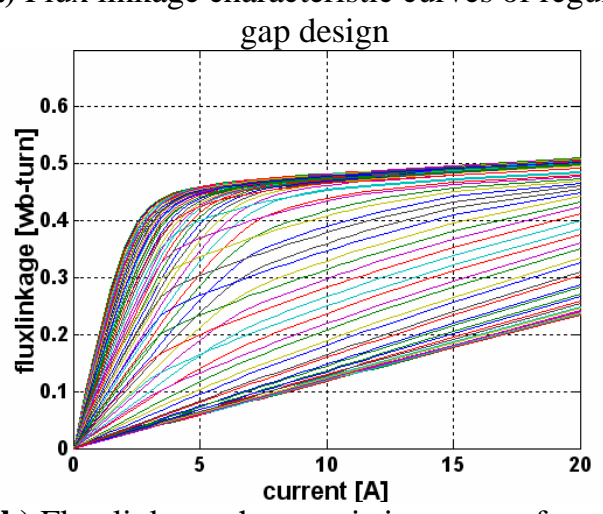

(5-b) Flux linkage characteristic curves of one step air gap design. 


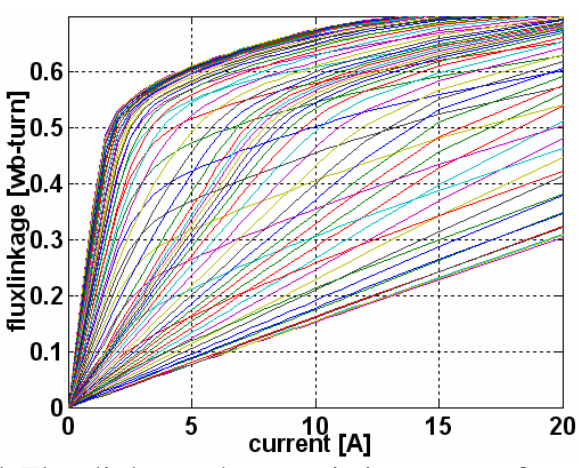

(5-c) Flux linkage characteristic curves of two steps

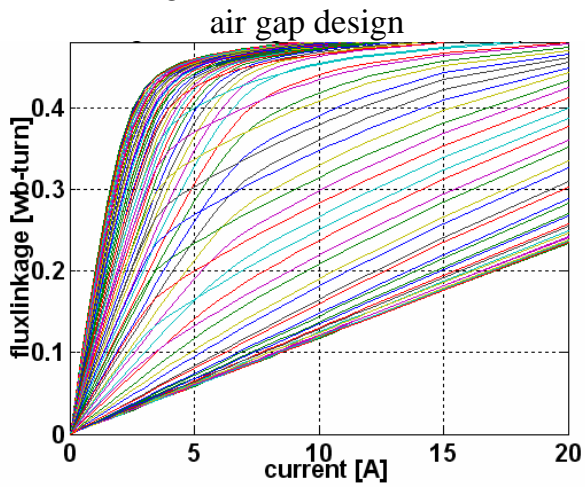

(5-d) Flux linkage characteristic curves of tapered air gap design

Fig 5. Flux linkage characteristic curves for the four different motor designs as a function of phase excitation current for different rotor position angles.

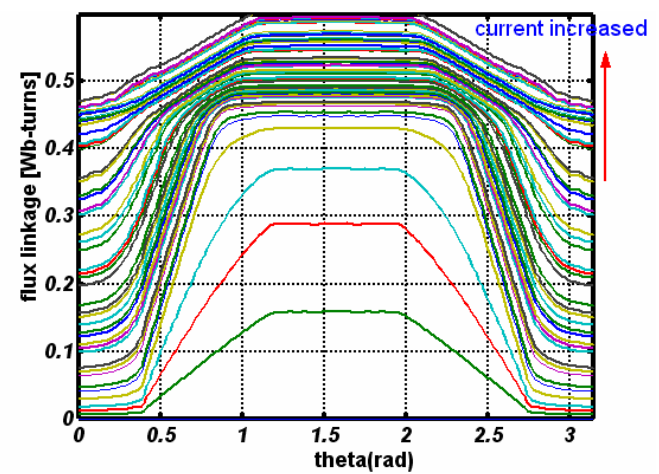

(6-a) Flux linkage characteristic curves of regular air

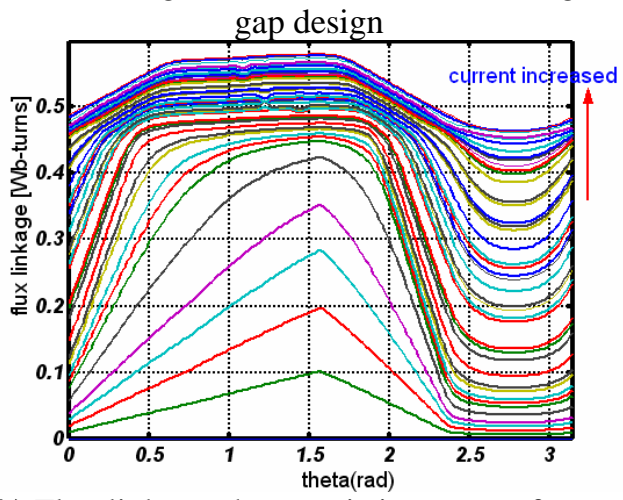

(6-b) Flux linkage characteristic curves of one step air gap design

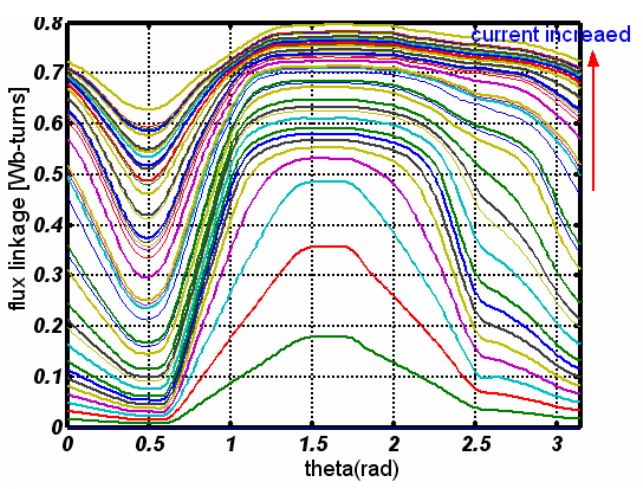

(6-c) Flux linkage characteristic curves of two steps air gap design.

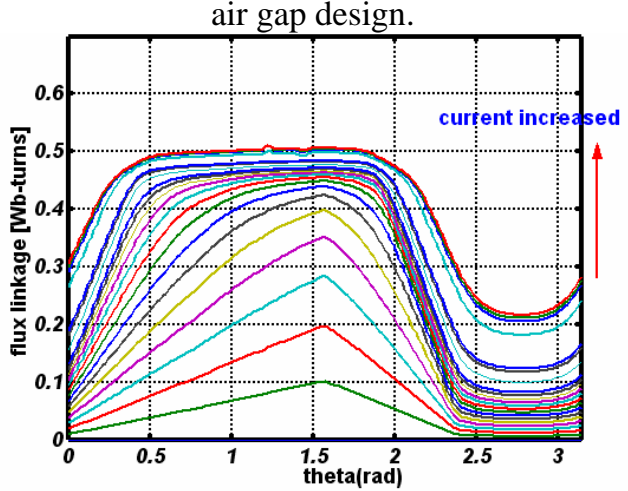

(6-d) Flux linkage characteristic curves of tapered air gap design

Fig. 6. Flux linkage characteristic curves for the four different designs as a function of rotor position angle for different phase excitation current levels.

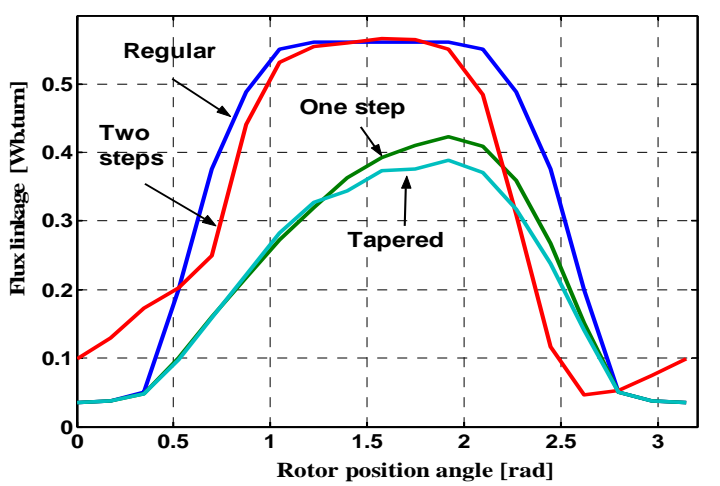

Fig. 7. Flux linkage as a function of rotor position angle for different designs at constant current of 3A.

\section{STATIC TORQUE CHARACTERISTICS}

The torque produced by a SRM is based on the rotor tendency to align with the exited stator poles. Like other electromagnetic devices static torque characteristics can be predicted from the basic energy conversion relationships. The co-energy Associated with any flux linkage curve at a certain rotor position $\theta$ is given by; 
$\mathrm{W}_{\mathrm{co}}\left(\mathrm{i}_{\mathrm{o}}, \theta_{\mathrm{o}}\right)=\int_{0}^{\mathrm{i}_{\mathrm{o}}} \psi\left(\mathrm{i}, \theta_{\mathrm{o}}\right) \mathrm{di}$

When the rotor moves from a certain initial position $\theta$ to $\theta+\Delta \theta$ the torque exerted is given by;

$\mathrm{T}(\mathrm{i}, \theta)=\left.\frac{\partial \mathrm{W}_{\mathrm{co}}(\mathrm{i}, \theta)}{\partial \theta}\right|_{\mathrm{i}=\text { constant }}$

From the previous expressions, the predicted static torque characteristics over a full rotor polepitch and at different excitation current levels can be obtained for different designs as shown in Fig.8. These static torque curves show clearly the differences in torque capability between the four different motor designs. The lower curves represent lower excitation, while the upper ones for higher current levels. Comparing the four sets of static torque characteristic curves, it is observed that, the two steps air gap design has the highest static torque followed by one step and tapered designs, while the regular air gap design possesses the lowest torque for the same current excitation.

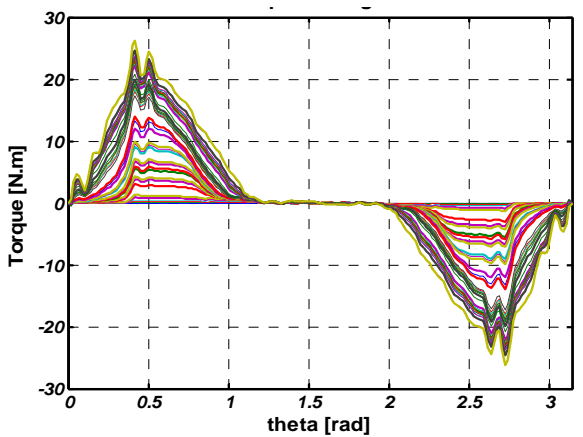

(8-a) Regular air-gap design.

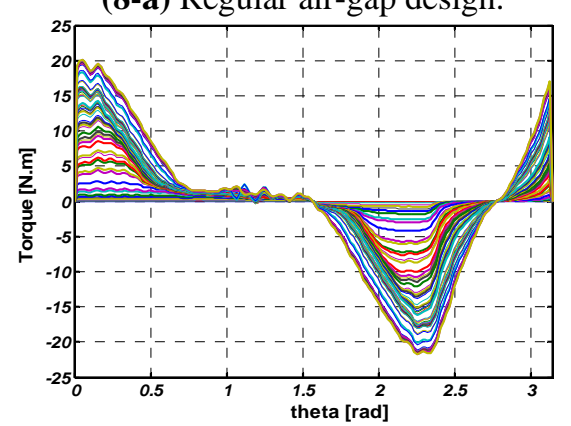

(8-b) One step air-gap design.

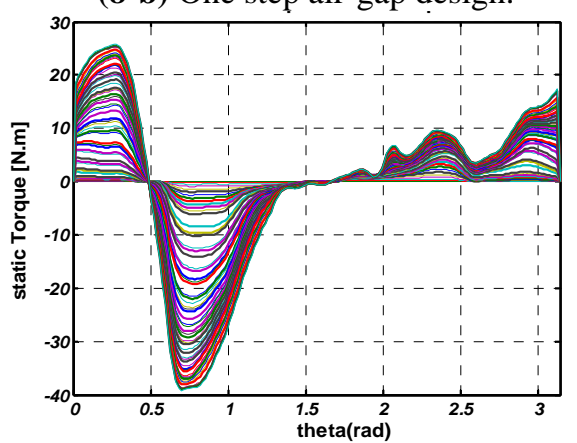

(8-c) Two steps air-gap design.

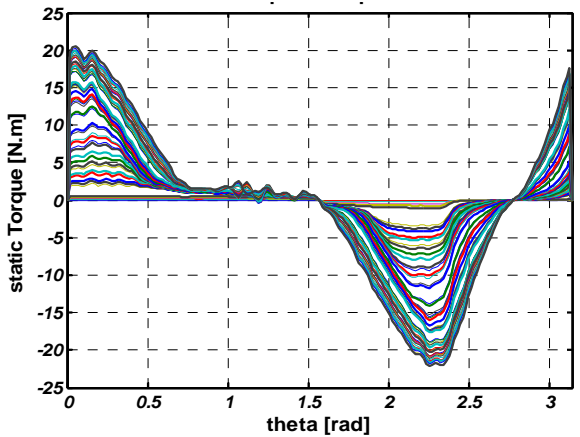

(8-d) Tapered air-gap design.

Fig. 8. Static torque for the four different motor designs

\section{PEFORMANCE ANALYSIS COMPUTER SIMULATION}

The voltage applied to any phase $\mathrm{k}$ at the rotor position $\theta_{\mathrm{k}}$ can be expressed as [19];

$$
\mathrm{V}_{\mathrm{k}}\left(\theta_{\mathrm{k}}\right)=\mathrm{R}_{\mathrm{k}} \mathrm{i}_{\mathrm{k}}+\frac{\mathrm{d} \psi_{\mathrm{k}}\left(\theta_{\mathrm{k}}, \mathrm{i}_{\mathrm{k}}\right)}{\mathrm{dt}} \quad \mathrm{k}=1,2
$$

where $\mathrm{R}$ is the phase resistance.

The voltage applied to the motor is usually obtained from a power electronic converter having a switching sequence locked with the rotor position angle. During each cycle, the power converter forces the voltage applied to each phase winding to alternate between three different levels. Initially a positive voltage is applied to the phase winding. At the end of phase duty angle $\theta_{\text {off }}$, a negative voltage is applied to the winding until the phase current decays to zero at $\theta_{\mathrm{ex}}$, after which applied voltage is reduced to zero. The phase voltage $V_{k}\left(\theta_{k}\right)$ applied to the phase winding $\mathrm{k}$ can be expressed as follows

$$
\mathrm{V}_{\mathrm{k}}\left(\theta_{\mathrm{k}}\right)=\left\{\begin{array}{cc}
+\mathrm{V}_{\mathrm{dc}} & \theta_{\text {on }} \leq \theta_{\mathrm{k}} \leq \theta_{\text {off }} \\
-\mathrm{V}_{\mathrm{dc}} & \theta_{\text {off }} \leq \theta_{\mathrm{k}} \leq \theta_{\text {ext }} \\
0 & \theta_{\mathrm{k}}>\theta_{\text {ext }}
\end{array}\right.
$$

where $\theta_{\mathrm{k}}=\theta+(\mathrm{k}-1) . \delta, \theta=\omega \mathrm{t}$ and the step angle is given by; $\delta=2 \pi / \mathrm{qN}_{\mathrm{r}}$, where $\mathrm{q}$ is the number of phases.

The performance for each motor configuration can be obtained using the family of the corresponding flux linkage-current curves $\psi(\theta, \mathrm{i})$ at different rotor positions which obtained by the FE analysis. These curves are rearranged and stored in the form of $\mathrm{i}(\theta, \psi)$ look-up tables. Using a time stepping numerical integration procedure applied to Eqn (21), the flux linkage of each phase is obtained. At each integration step the phase current is obtained with the aid of the stored $\mathrm{i}(\theta, \psi)$ data. The developed torque is also obtained by a time stepping procedure. For each step the phase co-energy is obtained by numerical integration of the $\psi(\theta, \mathrm{i})$ with respect to phase current: 
$\mathrm{W}_{\mathrm{k}}\left(\theta_{\mathrm{k}}, \mathrm{i}_{\mathrm{k}}\right)=\int_{0}^{\mathrm{i}} \psi_{\mathrm{k}}\left(\theta_{\mathrm{k}}, \mathrm{i}_{\mathrm{k}}\right) \mathrm{di}_{\mathrm{k}}$

From which the developed torque can be obtained by numerical differentiation of the $\mathrm{W}(\theta, \mathrm{i})$ with respect to the corresponding rotor position $\theta_{\mathrm{k}}$

$\mathrm{T}_{\mathrm{k}}\left(\theta_{\mathrm{k}}, \mathrm{i}_{\mathrm{k}}\right)=\frac{\partial \mathrm{W}_{\mathrm{k}}\left(\theta_{\mathrm{k}}, \mathrm{i}_{\mathrm{k}}\right)}{\partial \theta_{\mathrm{k}}}$

The total developed torque is obtained as the summation of the instantaneous torque developed by all phases.

$\mathrm{T}=\sum_{\mathrm{k}=1}^{\mathrm{q}} \mathrm{T}_{\mathrm{k}}\left(\theta_{\mathrm{k}}, \mathrm{i}_{\mathrm{k}}\right)$

A simulation based on this mathematical model as well as the data obtained from FE is implemented on the general purpose simulation package Matlab/Simulink. Throughout the present study, excitation pulses are initiated at the unaligned axis, while the pulse width is varied to study its effect on the operating performances of different designs. The pulse width is expressed by a ratio (duty ratio $\mathrm{Cr}$ ) defined as the ratio of the angle during which the excitation pulse is applied to the phase winding to the stator pole arc angle.

\section{RESULTS AND DISCUSSION}

The torque-speed characteristics are presented in Fig. 9. These characteristics are obtained at similar duty ratio of $\mathrm{C}_{\mathrm{r}}=1.1$. Both two-steps air gap and regular one produces the highest torque at all duty ratios, while one-step air gap and tapered one are comparable. It is also observed that two-stepped air gap has the highest torque at very low speeds which indicates a better starting capability. The regular air gap design has a lower torque at low speeds; however it becomes better at higher speeds. Both two-steps air gap and regular one are almost comparable at all operating speeds.

Figure 10 represents the current drawn from the dc source as a function of motor speed at the same duty ratio. The differences between the four designs from the point of view of there input current are clear. On this figure it is observed that the two-steps air gap design has the lowest current at all operating speeds, while the regular air gap design has the highest current almost at all operating speed. Both tapped air gap and one step air gap are comparable, however one step design draws a slightly lower current.

Torques per ampere curves for the different designs are represented in Fig. 11. From this figure it is observed that the two-steps design exhibits the highest torque per ampere, followed by the regular air gap design. Both one-step air gap and tapered one have comparable torque per ampere characteristics at all speeds, however one step is slightly better at low speeds. At high speeds these two designs along with the regular one are almost the same.

Figure 12 represents the torque/ampere versus the current drawn from the dc supply for different designs at constant duty ratio of 1.1. For all designs the torque/ampere has a maximum value at a certain current level. The maximum torque/ampere is obtained at a relatively small excitation current level for all designs except the regular one.

The efficiency of the four different designs is represented versus the operating speed, developed torque and input current respectively in Figs. 13, 14, and 15. From Fig 13 it is observed that for all designs the efficiency increases with the operating speed. This because the motor draws lower current at high speed which reduces the copper losses. The efficiency of two-steps design is higher at all operating speeds followed by the regular air gap. The motor efficiency represented as a function of the developed torque is shown in Fig 14, while Fig 15 represents the motor efficiency as a function of the input current. Since the copper losses increase with the current the efficiency gets lower with higher current and higher torque. On both figures it is observed that regular air gap and two-steps one have higher efficiency while one-step and tapered one have lower efficiency at all operating speeds.

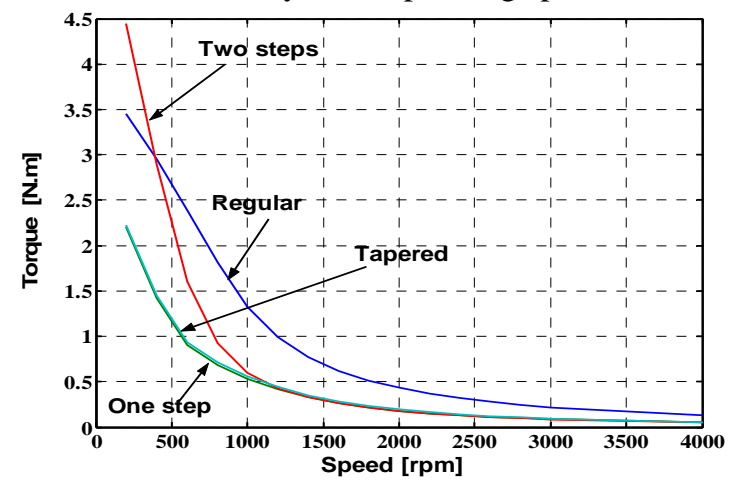

Fig. 9 Torque-speed characteristics for different designs at a duty ratio $\mathrm{C}_{\mathrm{r}}=1.1$

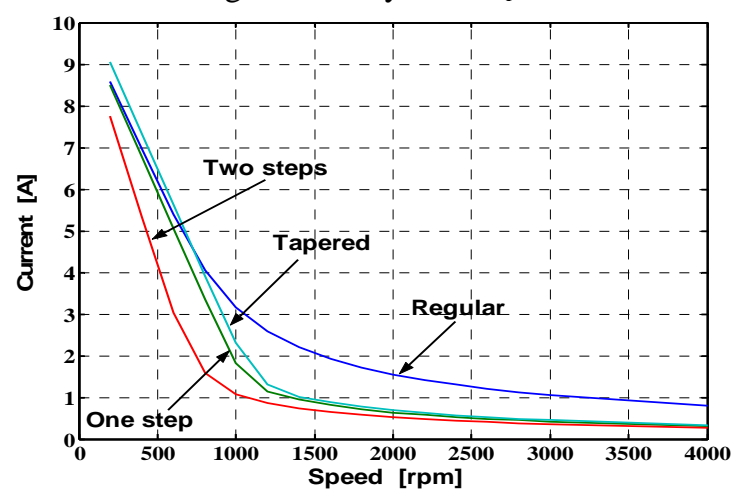

Fig. 10 Current-speed characteristics for different designs at a duty ratio $\mathrm{C}_{\mathrm{r}}=1.1$ 


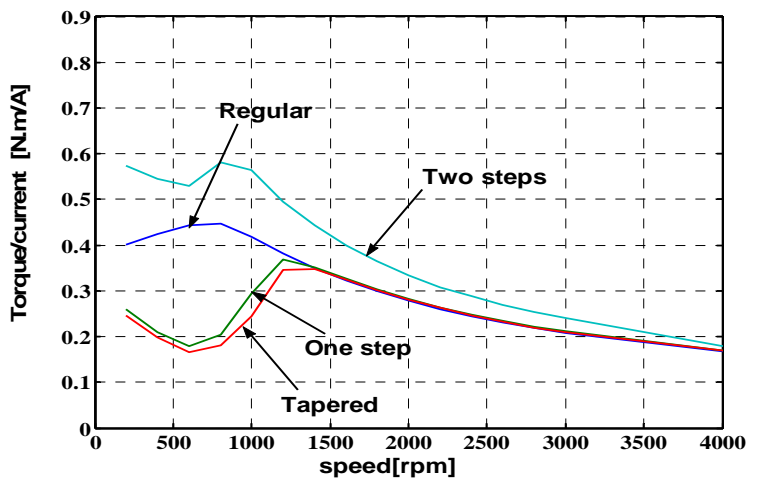

Fig. 11 Torque/ampere versus speed characteristics for different designs at a duty ratio $\mathrm{C}_{\mathrm{r}}=1.1$

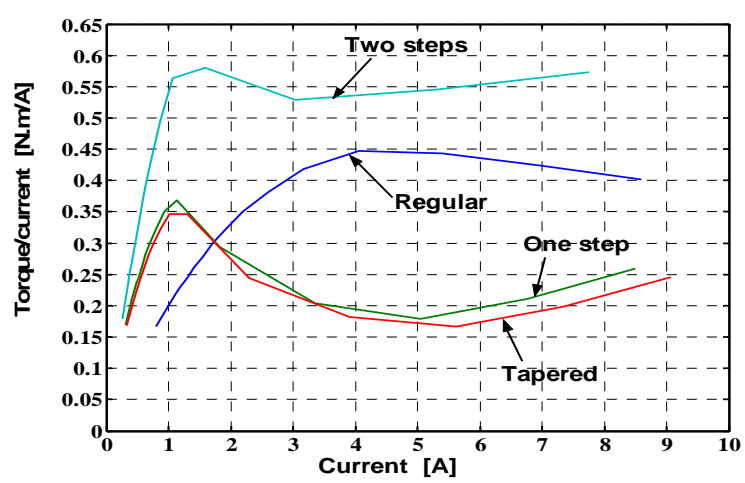

Fig. 12 Torque/ampere versus current characteristics for different designs at a duty ratio $\mathrm{C}_{\mathrm{r}}=1.1$

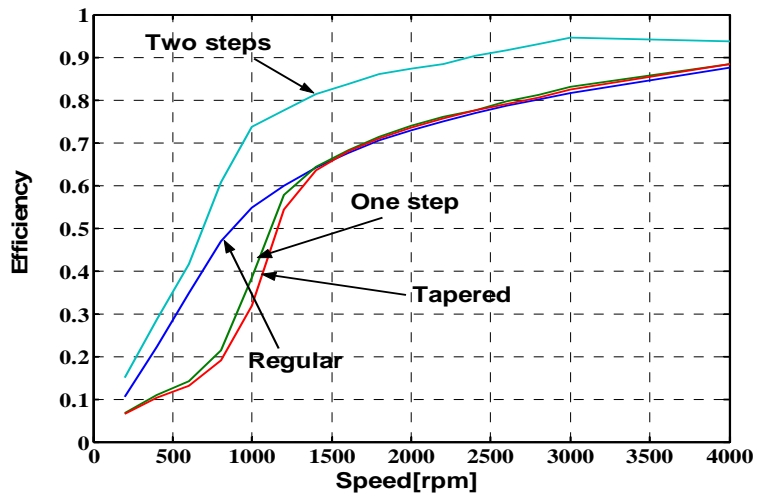

Fig. 13 Efficiency versus speed for different designs at a duty ratio $\mathrm{C}_{\mathrm{r}}=1.1$

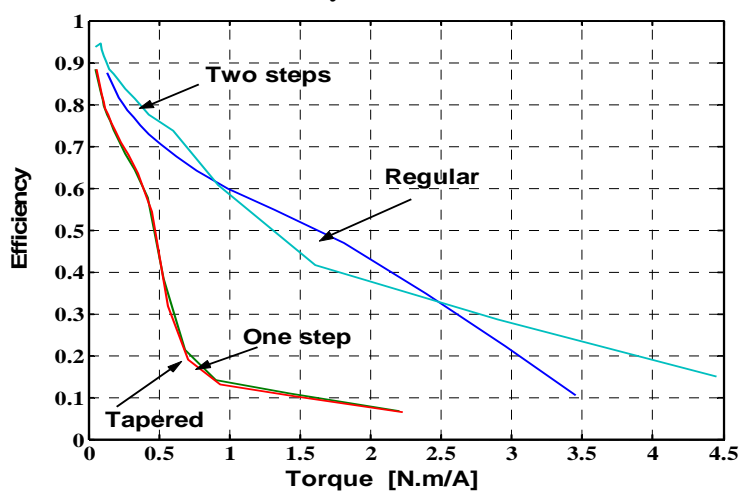

Fig. 14 Efficiency versus torque for different designs at a duty ratio $\mathrm{C}_{\mathrm{r}}=1.1$

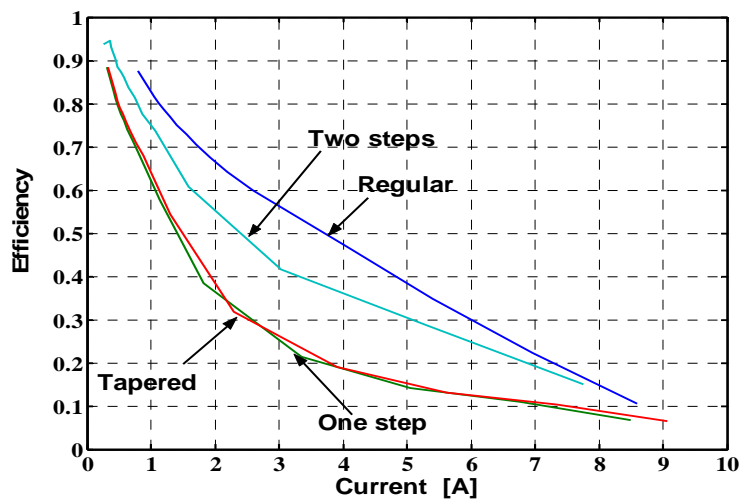

Fig. 15 Efficiency versus current for different designs at a duty ratio $\mathrm{C}_{\mathrm{r}}=1.1$

\section{CONCLUSION}

A comparison between four different designs of a two-phase SRM has been presented. The study is based on finite element analysis of the magnetic circuit of these designs. The flux linkage and static torque characteristics have been obtained for each design and used to predict the operating performance of these designs. A comparison was held between the four different designs under investigation from the point of view of torque production, current drawn from the dc mains, torque per ampere capability, and motor efficiency. It has been found that different motor designs have different capabilities of torque production. Both two-steps air gap and regular one produces the highest torque at all duty ratios, while one-step air gap and tapered one are comparable. The regular air gap design has a lower torque at low speeds; however it becomes better at higher speeds. The two-steps air gap design draws the lowest current, while the regular air gap design has the highest current almost at all operating speeds. The two-steps design exhibits the highest torque per ampere, followed by the regular air gap design. Both one-step air gap and tapered one have comparable torque per ampere characteristics at all speeds, however one step is slightly better at low speeds. At high speeds these two designs along with the regular one are almost the same. The efficiency of two-steps design is higher at all operating speeds followed by the regular air gap, while one-step and tapered one have lower efficiency at all operating speeds. In conclusion, the two-steps air gap design has the best over all performances over the other motor designs under investigation.

\section{REFERENCES}

[1] N. N. Fulton, and P. D. Webster, "The Development and Application of 2-Phase Switched Reluctance Drives", Eighth International Conference on Electrical Machines and Drives (EMD97), 1-3 Sept. 1997, PP 366370 
[2] Ragi Hamdy, John Fletcher, and Barry W. Williams, "Bidirectional Starting of a Symmetrical Two-Phase Switched Reluctance Machine", IEEE Transactions On Energy Conversion, Vol. 15, No. 2, June 2000, PP 211217

[3] I. E. Chabu, S. I. Nabeta, and J. R. Cardoso, "Design Aspects of 4:2 Pole 2-Phase Switched Reluctance Motors", 0-7803-5293-9/99 \$10.00 (C) 1999 IEEE, PP 63-65

[4] M. A. El-Khazendar, J. M. Stephenson, “Analysis and Optimisation of the 2-phase Self-Starting Switched Reluctance Motor”, Proceedings of International Conference on Electric Machines'86, Munich, September 1986, PP 1031-1034.

[5] R. Hamdy, John E. Fletcher, B. W. Williams, and S. J. Finney, "High-Speed Performance Improvements of a Two-Phase Switched Reluctance Machine Utilizing Rotor-Conducting Screens", IEEE Transactions On Energy Conversion, Vol. 17, No. 4, December 2002, PP 500-506

[6] J. O. Fiedler, R. W. De Doncker, "Designing Low-Cost Switched Reluctance Drives for Fan Applications", Second International Conference on Power Electronics, Machines and Drives, 2004. (PEMD 2004). (Conf. Publ. No. 498), PP 758-762

[7] J.M. Stephenson and G.C. Jenkinson, "SinglePhase Switched Reluctance Motor Design", IEE Proc.-Electr. Power Appl., Vol 147, No 2, March 2000, PP 131-139

[8] G.C. Jenkinson, J.M. Stephenson, "Starting of a Single-Phase Switched Reluctance Motor", Ninth International Conference on Electrical Machines and Drives, 1-3 Sept. 1999, PP 391395

[9] D.A. Torrey, X.M. Niu, E.J. Unkauf, "Analytical modelling of variable-reluctance machine magnetization characteristics" IEE Proc. Electr. Power Appl, Vol. 142, No. 1, January 1995, PP 14-22

[10] T. S. Low, H. Lin, and S. X. Chen, “Analysis and Comparison of Switched Reluctance Motors With Different Physical Sizes Using A 2D Finite Element Method”, IEEE Transactions on Magnetics, Vol. 31, No. 6, November 1995, PP 3503-3505

[11] Yasuaru Ohdachi, Yashihiro Kawase, Yutaka Miura and Yoji Hayashi, "Optimum Design of
Switched Reluctance Motors Using Dynamic finite Element Analysis", IEEE Transactions On Magnetics, Vol.33, No.2, March 1997, PP 20332036.

[12] Stkphane Brisset and Pascal Brochet," Optimization of Switched Reluctance Motors using Deterministic Methods with Static and Dynamic Finite Element Simulations, IEEE Transactions On Magnetics, Vol. 34, No. 5, September 1998, PP 2853-2856

[13] Jin Woo Lee, Hong Seok Kim, Byung Il Kwon, and Byung Taek Kim, "New Rotor Shape Design for Minimum Torque Ripple of SRM Using FEM", IEEE Transactions On Magnetics, Vol. 40, No. 2, March 2004, PP 754-757

[14] Farzad R. Salmasi and Babak Fahimi ,"Modeling Switched-Reluctance Machines by Decomposition of Double Magnetic Saliencies", IEEE Transactions On Magnetics, Vol. 40, No. 3, May 2004, PP 1556-1561

[15] Wei Wu, Bruce A.Kalan and Howard C.Lovatt, “ Time-Stepping Analysis of a Switched Reluctance Motor by Coupling Electrical Circuit and Electromagnetic Finite Element Methods”, Proc of the Sixth International Conference on Electrical Machines and Systems (IEEE Cat. No.03EX782) 2003, PP 728-731.

[16] D. Rodger, H. C. Lai, R. J. Hill-Cottingham, and P. C. Col, "Some Tricks for Modeling Rotating Electrical Machines Using Finite Elements", IEEE Transactions on Magnetics, Vol. 40, No. 2, March 2004, PP 802-805.

[17] Matthew N. 0. Sadiku, “A Simple Introduction to Finite Element Analysis of Electromagnetic Problems”, IEEE Transactions on Education, Vol. 32, No. 2, May 1989, PP 85-93.

[18] M. M. Khater, W. A. Afifi, M. A. El-Khazendar, "Operating Performances of a Two-Phase Switched Reluctance Motor", 11th International Middle East Power Systems Conference (MEPCON), 19-21 December 2006, El-Minia, Egypt, PP 636-642.

[19] M. M. Khater, H. Abdel-Maksoud, and S. ElDoheimy, "Performance of Three-Phase Switched Reluctance Motors With Different Structures: Comparative Study", The 10th International Middle-East Power System Conference, MEPCON'2005, Port Said, EGYPT, 13-15 December 2005, PP 239-245 